\title{
Keeping it clean
}

\section{Negative emissions are necessary to meet ambitious climate targets, but in order to achieve these we need both technological advances and an economic environment that promotes such activity.}

Year on year, climate events continue to be record-breaking, with many 'firsts' reported. What were once considered extremes seem to be occurring with increased frequency and these events emphasize how the climate is changing. On a positive note, 2016 saw a milestone that was welcome - following the signing of the Paris Agreement on 12 December 2015, the agreement entered into force on 4 November 2016, thirty days after the threshold was passed. With 123 parties having ratified the agreement, representing $80 \%$ of global emissions ${ }^{1}$, this comfortably exceeds the required threshold of 55 parties representing at least $55 \%$ of total global greenhouse gas emissions. This agreement was long awaited and raises hope that action will follow.

However, having the agreement enter into force is not enough; with political change in many parts of the world, nothing is set. For example consider the uncertainty of the United States commitment to the agreement with the recent election of Donald Trump and his public statements regarding the agreement (see Commentary by Ben Sanderson \& Reto Knutti, page 92, for discussion of what such comments and resultant actions may mean).

In order to meet the targets set out in the agreement, it's not enough to simply reduce emissions. In order to meet the ambition of $1.5^{\circ} \mathrm{C}$ we need to have negative emissions, which will be achieved through the removal of $\mathrm{CO}_{2}$ from the atmosphere. This is known as carbon capture and storage (CCS). The carbon is captured at the point of emission, such as at power plants, and is transported for permanent storage, typically through injection into stable geological strata, locking it deep underground. For example, Peter McGrail and co-authors report on the successful injection and stabilization of 1,000 tonnes of $\mathrm{CO}_{2}$ in natural basalt, with 2 years of tracking post-injection showing mineralization of the injected $\mathrm{CO}_{2}$ in the field ${ }^{2}$.

However, progress on CCS implementation has been slow, as highlighted in a Perspective published in Nature Energy last year ${ }^{3}$. Although there have been a number of large-scale projects testing the technology over recent years as evidenced by the McGrail et al. study, movement beyond this demonstration

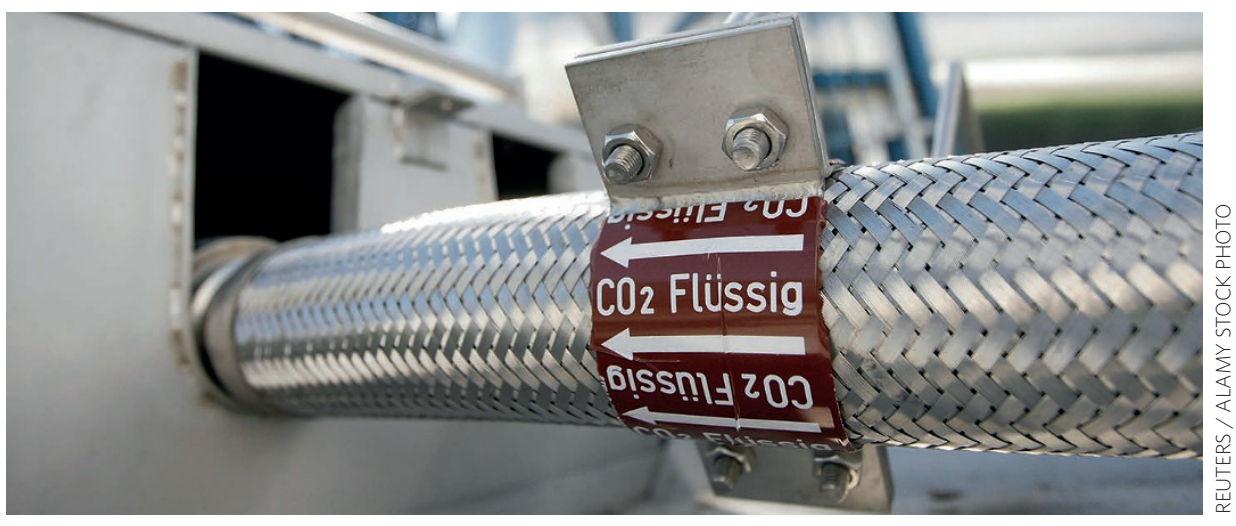

stage to real world implementation has not followed. Whilst all the components of integrated CCS systems are available, the economics currently do not make it an attractive option ${ }^{4}$. CCS tends to rely on subsidies as traditionally there are high costs associated with the technology and the transport and storage of the captured gas. With greater policy ambition, there may be increased incentive to implement, which could create the right economic environment.

However, it is not clear that we have the technology needed for large-scale implementation. A Letter in this issue (page 118) sets out interrelated indicators for tracking progress towards the Paris Agreement as well as future ambition. Glen Peters and colleagues show that whilst renewables in the form of wind and solar power have reduced emissions, there are still technological advances needed in the areas of CCS to meet 2030 targets and the longerterm goal of net-zero emissions. It is not clear that enough research is happening in these areas. As Christopher Green discusses in an accompanying News and Views (page 98) we need approximately a 5\% decline in carbon emissions per year, which taken with a $2 \%$ increase in gross domestic product equates to around a $7 \%$ decline in the carbon intensity of economic activity every year to 2050. Is this achievable? Considering that in recent years, the decline has been in the range of $1-2 \%$, it will need new thinking and advances in the field to be able to meet the levels needed.

An interesting, and alternative, advance in CCS reported early this year is the conversion of captured carbon into sodium carbonate, also known as soda ash - a chemical then used in the manufacture of glass and other industrial processes. The technology comes from Carbonclean and has been installed at Tuticoren Alkali Chemicals in southern India, capturing the emissions from the plant's coal-powered boiler ${ }^{5}$. This advance shows great promise, with estimates that the technology could trap up to 60,000 tonnes of carbon per year. Even more promising is that this has been achieved without government subsides: in fact, it was reported that it cost only US\$30 per tonne of $\mathrm{CO}_{2}$ captured. Additionally it provides the chemical ready for use and the plant owners with a reliable source of $\mathrm{CO}_{2}$.

New ideas such as this may be what are needed to develop the right technology. Additionally, private sector funding may enable research that could face funding cuts under the new US administration to continue (page 92). For example, the Breakthrough Energy Coalition, fronted by Bill Gates and numerous other billionaires, has announced a US\$1 billion investment fund (http://www.b-t.energy) aiming to generate new ideas on clean energy. These new ways of thinking are important at a time when maintaining momentum is essential to keeping on track with climate mitigation.

References

1. Paris Agreement Ratification Tracker (Climate Analytics, accessed 13 January 2017); http://go.nature.com/2jR1lra

2. McGrail, B. P. et al. Environ. Sci. Technol. Lett. 4, 6-10 (2017).

3. Reiner, D. M. Nat. Energy 1, 15011 (2016).

4. Bruckner, T. in Climate Change 2014: Mitigation of Climate Change (eds Edenhofer, O. et al.) Ch. 7 (IPCC, Cambridge Univ. Press, 2015).

5. Harrabin, R. Indian firm makes carbon capture breakthrough. The Guardian (4 January 2017). 